\title{
The Difference of Second/ Foreign Language Acquisition and Learning for Adults and Children (A qualitative study on Steinberg's research (1982 and 1993))
}

Win Listyaningrum Arifin

IAIN Salatiga, Salatiga, Indonesia

Q $\quad$ winlistyaningrum@iainsalatiga.ac.id

\begin{abstract}
This paper is based on the research by Steinberg in 1982 and 1993 to answer the question of how children and adults control second/foreign languages with the focus on giving more reasonable answers whether the children are better than adults in the mastery. The process of obtaining second language can be from the natural/social/acquisition and from class/learning. The learner's internal factors such as the role of the first language, motivation, and attitudes are also very important in determining the success of second language acquisition. Steinberg et al. try to draw the conclusion that the decrease in memory power for learners is associated with age. Age cannot be a benchmark for the success rate of mastering a second/foreign language other than mother tongue as long as the involved people have desire to use the foreign language or the second language for the purpose of integrating and socializing.
\end{abstract}

\section{KEYWORDS:}

Second/foreign language acquisition;

Adult;

Children;

\section{INTRODUCTION}

“Early in life, humans have a superior capacity for acquiring languages. If the capacity is not exercised during this time, it will disappear or decline with maturation. If the capacity is exercised, however, further language learning abilities will remain intact throughout life" (Major, 2014). It has become a speculative perspective when some people claim that children are better than adults in learning a second language besides their original language. This perception is based on direct observations that young language learners tend to be faster in acquiring 
language in addition to the original language only through habits and without a formal learning.

Most of us believe that children are better than adults in learning second language. This statement is supported by common observation stated that young second-language learners seems to be able to learn another language quickly by exposure without teaching. Steinberg in Suryantari (2018) states that there are some factors involved in second-language. Generally, it is said that children are better learners than adults. When considering second language acquisition, a child introduced to a second language at the same time as an adult will, in almost every case, acquire a much better pronunciation. Young learners will also do better when it comes to grammar skills and fluency as stated by Lightbrown \& Spada in Oroji \& Ghane (2014)

This paper focuses on giving more reasonable answers to questions about whether children are better than adults in mastering the second language. This paper is based on research conducted by Steinberg in 1982 and 1993 to answer the question of how children and adults control second languages and how these barriers interfere with the level of mastery of the target language (second language).

For Steinberg, there are three main factors that influence the acquisition of a second language, namely psychological factors, social situations and other psychological determinants. The psychological conditions of learners are intellectual capacity, memory and learners motor skills in analyzing grammatical, vocabulary, and fluency structures. The social situation divides the learner based on the environment in which the learner lives. Social interaction, learner experience and the determinant environment both naturally and formally (in the classroom) describe the relationship between the learner and his physical environment. The learner's internal factors such as the role of the first language, motivation, and attitudes are also very important in determining the success of second language acquisition.

Next, I will try to find out about how these factors really answer the questions raised by Steinberg in his hypothesis of the study about the basic 
psychological factors influencing the acquisition and learning of second languages.

\section{RESEARCH METHOD}

This research is a library study to present a qualitative approach of a certain topic. This paper is aimed at answering the question about the different process of second language acquisition and learning between adults and children. The paper presents on how adults and children control the barriers in mastering other languages aside of their mother tongue. This paper also reveals the fact whether children are better and easier to master second language than adults. Summing up, this paper answers the questions done by Steinberg dealing with the acquisition and learning process between adults and children in mastering second language.

\section{FINDING}

Below is a table based on the Steinberg (1982) study about the influence of psychological and social factors on second language acquisition and learning in children and adults.

\begin{tabular}{|c|c|c|c|c|c|c|}
\hline & \multicolumn{4}{|c|}{ Psychological factors } & \multicolumn{2}{|c|}{ Social factors } \\
\hline & \multicolumn{2}{|c|}{ Intellectual } & \multirow[b]{2}{*}{ Memory } & \multirow[b]{2}{*}{$\begin{array}{l}\text { Motor } \\
\text { skills }\end{array}$} & \multicolumn{2}{|c|}{ Situation } \\
\hline & Inductive & Explicative & & & Natural & $\begin{array}{l}\text { Classroo } \\
\mathrm{m}\end{array}$ \\
\hline $\begin{array}{l}\text { Children } \\
\text { under } 7\end{array}$ & High & Low & High & High & High & Low \\
\hline $7-12$ & High & Medium & Med/high & Med/High & Medium & Medium \\
\hline $\begin{array}{l}\text { Adults over } \\
12\end{array}$ & High & High & Medium & Low & Low & High \\
\hline
\end{tabular}

An explanation of how and how many levels of psychological and social factors affect the mastery of the second language will be described in detail in the contents of this paper. 


\section{DISCUSSION}

\section{Intellectual Process: Exploration and Induction}

Exploration and induction are two factors that influence the intellectual process in terms of the learner's syntactic ability to the target language. Meanwhile, induction is the process of transferring rules and grammatical structures of the target language to learners. The language of instruction used in the process of exploration is the use of the learner's first language. This is intended to make it easier for students to understand and master the second language because the language learning intake of the learner is still limited. Thus, learners can apply and use the grammatical rules of the target language properly. The disadvantages of using the exploration model also arise when the speed and the accuracy of the information obtained by learners varies. The application is very helpful for language learners in mastering languages other than mother tongue but only for those who are categorized as slow learners. Meanwhile, fast learners may assume that the method of learning is a tedious activity that can hinder the process of learning and acquiring foreign languages.

Another weakness that arises is that the exploration cannot fully explain other languages because of the different grammatical rules between mother tongue and foreign languages. Another reason that arises is that standard rules in the target language are sometimes not recorded, making it difficult for language learners to learn. Although the exploration model uses introductory mother tongue in teaching foreign languages, it turns out this method is not successful for children. The reason is that even parents rarely use standard rules in native languages when teaching foreign languages whether they are in simple sentences or word formations. Usually, children look for standard rules in the original language by learning and analyzing themselves or self-taught through the process of induction.

Independent analysis which is then known as self-discovery is the core of the induction process. Children who often speak because they are skilled at listening to and memorizing second language vocabulary will find it easier to analyze and find the standard rules in the second language. As explained by Krashen (1981) that children receive a second language through natural processes long before the children are involved in formal education activities (understanding the concept of 
"here and now" in the form -ing, plural form, auxiliaries, etc.). Adults who learn a second language will also look for answers to questions in the target language through the process of induction. The difference is that adults are better prepared because they have had prior provision of knowledge about a second language. The process of induction as a means of self-analysis is used to analyze and find generalizations or rules in the language. English is learned by the process of second language acquisition. In fact, a young child can learn a second language faster than an adult can learn the same language (Hoque, 2017)

Even so, exploration is considered to accelerate the process of language learning because it is useful towards understanding simple sentence structures. While induction tends to dwell on understanding complex structures. The application is very useful for learners who are still in the level of understanding structured sentences from subjects and predicates where the use of time adverbs or place adverbs is placed at the beginning of the sentence.

\section{Memory}

Vocabulary is an important part of mastering and learning a second language. Why? Because vocabulary is words that should be remembered by learners. The vocabulary form is not only a traditional word but also phrases that in English are often referred to as phrasal verbs, verb-adverb combinations (particle phrases), two word verbs, three part verb or multi word verbs. The vocabulary is finally grouped as nouns, verbs, adjectives, prepositions, adverbs, and so on. So that the ability to remember vocabulary is very important in the process of acquisition and learning of second languages.

Memory is generally associated with neurology or neurolinguistics in learning languages when it is related to the foreign language mastery aside of mother tongue. Speech production or more so-called language lies not only in the left brain but also in the human right brain. Eventhough, many experts claim that the left brain is more dominant in the language production than the right brain. In his book Krashen, states that someone whose left brain is dissected after experiencing apahasia can still produce speech as the right brain is functioning. Because the right brain helps the patient in making speech sounds or languages stored in the left brain (Krashen, 1981). He added that the right hemisphere engaged in the 
language process of human language ability. Otherwise, if the right hemisphere experiences damage as the person suffers a stroke, he will lose all language ability.

The ability to remember vocabulary is also closely related to the learner's experience. The vocabulary that is remembered is usually through the process of being heard then connected with the physical or abstract form of what is heard. To be easy to remember, usually learner does not only receive or hear once or twice for the vocabulary. The desire to practice and use vocabulary in speaking is also very important to memory sharpness.

Memory is also very important when a learner learns the structure and rules of the target language. Usually the standard rules of a particular grammar can be a barrier for someone so that memory cannot be separated from the learner's ability to master languages other than his mother tongue. Memory can also deliver the learner to an analytical action when he is asked to explain the target grammar correctly, including the time of the structure (tense), noun that must be used when meeting certain verbs and so on. Memory also helps learners to identify sentence forms. However, given the flexibility of declarative memory it, too, should underlie grammatical functions, for example, by learning rules or chunks (e.g., "the cat"). A range of factors could lead to an increased dependence of grammar on declarative memory. Of interest here, since learning in declarative memory seems to improve during childhood (with possible concomitant declines in procedural learning and/or consolidation), later learners of language are predicted to depend particularly on declarative memory for grammar, while native speakers should rely more on procedural memory. Additionally, grammar should rely more on declarative memory at earlier than later stages of learning within an individual language learner, since learning in declarative memory takes place more quickly than in procedural memory. For these reasons, adult second language learners should initially rely particularly on declarative memory for grammar, although, with increasing L2 experience, they should eventually depend substantially on procedural memory (Hamrick, Lum, \& Ullman, 2018)

Memory ability in children between the ages of 5-6 years still shows memory capacity at peak memory levels. Decreasing memory ability begins to appear when children are around 8 years old and over 12 years old. So there 
appears to be a categorization of children's memory based on ages under 7 years and between the ages of 7-12 years. Harley and Doug (1997) investigate students in the immersion class revealed that older children began to use cognitive abilities in analyzing the rules of syntax in second languages, while younger children tended to still use their good memory skills in vocabulary in learning a second language. This happens because children between 7-12 years have difficulty remembering vocabulary that has been obtained so that they often do syntactic analysis when learning.

The next reason why memory capacity decreases is that second language learning will become more complex following the learners' ages between 15 or 20 years. But this decline in language skills is even more linked to linguistic processes that are deficits and not related to memory (Bloom, Mullins, \& Paternostro, 1996). Finally Steinberg et al. try to draw the conclusion that the decrease in memory power for learners is associated with age. As young learners' cognitive abilities are still undergoing development, it is also possible that the role of WM functioning in L2 writing performance changes across grade levels. Therefore, it is imperative to investigate the role of WM in integrated tasks performed by younger learners for whom test results might determine their educational and professional future. Research on the effects of cognitive capacity limitations on various types of writing tasks might also yield useful information for teachers by helping them identify learners who might need additional support with certain types of tasks (Michel et al, 2019).

\section{Motor skills or abilities}

Good pronunciation is an important part of learning a foreign language. This ability is closely associated with the learner's articulation abilities and the ability to control the bones that support speech organs. Motor skills are a terminology of psychology to describe the use of bones in carrying out certain activities of a general nature such as walking into a more specific skill e.g. writing and speaking. The speaking activity includes articulation functions such as the mouth, lips, tongue which is controlled by the bones under the command of the brain. The articulation function must do something at the right time so that the sound that comes out is also more accurate. 
Motor skills are also inseparable from one's maturity. While learner maturity is also inseparable from emotional control, situations and so on. In order for learners to achieve a high level of mastery in terms of motor skills, learners must start at an early age. Because when learners reach 12 years of age, the ability to acquire motor skills also begins to decline. Even when someone has reached the age of 15 years, increasing motor skills will be very complicated. This is also due to changes in function in the brain. Hormonal changes in a person who has reached puberty are also thought to affect a person's motor skills despite their speculative nature. The conclusion is, when age increases ultimately affect the decline in motor skills, the learner's level of articulation will also be disrupted. Meanwhile, children will actually improve their fluency because their age still shows flexibility in motor skills. Oyama (1976) point out that someone who learns foreign languages at a very early age will pronounce the vocabulary of a foreign language as a native speaker accent. Oyama studied immigrant from Italy, the younger the children the more accent they were with native speakers. Conversely Italian immigrant children who come to the United States after age 12 tend to be less fluent in pronunciation. The length of stay does not affect the ability of articulation. Children tend not to use mother tongue as a filter so that the ability of their articulation can still be corrected when there is pronunciation.

\section{Conclusion of psychological factors in influencing second language learning}

Based on the table that has been shown, the variables in this study are induction, explanation, memory and motor skills. Respondents were divided into three age groups namely children under 7 years of age, children between the ages of 7-12 years, and adults over the age of 12 years. In induction variables, the level is high and is not limited by age differences. But the highest level according to the induction variable is those who fall into the adult category (over 12 years) because they are able to analyze the syntactic structure in the second language.

Variable explaining the level increases with age. Children under 7 years old have low levels, followed by children aged 7-12 years at the middle level and high levies at the age of 12 years. This is because the younger the child the more difficult it is to understand abstract and complex explanations. The next variable 
is memory. In young children the level is high but tends to go down to the medium level or fixed and will go down to the medium level when the child is 7-12 years old. Age factor determines the level of memory ability. Unfortunately, the category for adults is only limited to the categorization of the age above 12 years so that they cannot distinguish the level of memory ability when the child is in his teens or in the actual age of the age of 30 . The last variable driving psychological factors is motor skills. The tendency to decline from low to high levels indicates that mastery ability is influenced by age factors. The older a student is, the harder it is to pronounce words behaving in a fluent manner.

\section{Social situations that affect second language learning}

Although many social situations can affect the learning process and second language acquisition, Steinberg et al. try to limit social situations that affect second language learning, namely natural situation and class situation.

\section{Natural Situation}

The way to teach English both as a second language and a foreign language is diverse. Second language acquisition is often aimed at children who learn English naturally (informally). Steinberg stated that children living in other countries learn foreign languages without going through explicit learning but through interaction with playmates. He also added that children learn a second language faster than learning the first language. The question that might arise is can adults do the same thing as children in learning a second language if they are given the opportunity even with relatively almost the same time? Actually both children and adults have the same opportunity to learn foreign languages in addition to their first language. The difference lies only in the method used by both children and adults. What's more, the method also depends on the age factor which influences the decrease in social interaction which actually really supports foreign language learning.

The second language or foreign language of children becomes increasingly organized and good because the children streamline and optimize the environment as a medium for learning foreign languages. For example, these children will actively ask friends when they have difficulty understanding some vocabulary, and children like to imitate the language of their friends who are accentively and 
fluently dialects. They usually tend to interact socially rather than using language. For example, children with different language backgrounds (all Indonesians) will play and share toys while the use of language during play tends to be abandoned. In other words, both children and adults can learn a second language in natural situations, only the difference is fluency products. Children can follow native speaker accents while adults do not.

In natural situations where the role of language skills is very important, adults who do not have enough foreign language skills while living in a foreign country will make these adults isolated in association. This is not only experienced by adults but also children of first puberty. Similarly, native speakers tend to stay away from people who are in different languages. In social interaction, language plays an important role so that when a person is unable to speak according to the speaker, the association is automatically limited. In interacting cultures, according to Preston (1989), children aged 7-12 years tend to only be able to accept social norms in a certain area, while children under the age of 7 tend to be able to accept both culture and language in an area. The biggest obstacle about language learning is experienced by those in the age of 12 years or adults who tend to be confident in their identity and culture even though they are in another country.

Schumann (1978) in the Acculturation Model of language learning states that the level of mastery of one's language is influenced by the ability to adapt to a new environment. The more a person can acculturate to the new environment, the greater the language contact with the surrounding community, thus increasing the chance for natural language acquisition. Unfortunately this opportunity is more often used by children so they often hear and express target language skills in conversations with native speakers.

The habit of using language both by children and adults will have a direct influence on the process of language acquisition. When someone is in another country, surely the frequency of using mother tongue tends to be used less frequently, so the most dominant language usage is local language. If an ordinary conversation fails, this will affect the process of acquiring foreign languages for both children and adults. Simplification of speech is often done by adults when talking with children. Conversely, simplification of speech by adult learners may be 
done when the conversation is too heavy because of the constraints of mastery of a particular language. However, simplifying the context of speech can help learners to remember their memory and applications, especially for children and adults. Exposure to use the target language with native speakers or people who are not native but are good for the target language will be beneficial for both children and adults in naturally acquire and master the language.

\section{Class Situation}

Classes for foreign language teaching are usually special classes in the form of formal ones. Teachers are people who know the second language or foreign language well and learners in the class are those who want to learn the language. Usually the learner acts in accordance with the direction of the teacher, so that the teacher has a contribution to the situation of happiness in the classroom. Everything that happens in the language class has been structured and planned so that spontaneity is rare. The linguistic situation created as in the original environment such as outside the classroom activities by the use of foreign languages between learners through games will help learners in language acquisition and learning.

The teacher also plans a group of language teaching model so that language acquisition can run well and the desire of learners to be active in the class is also built. Learners are also given activities to make homework that the concentration of foreign language learning is more developed. It is expected that learners are accustomed to language teaching and consider teaching foreign languages as academic subjects. Thus, they are familiar with all grammatical structures and other rules in foreign languages. Consequently, the class should be comfortable, cheerful and teaching is often done through the use of games to convey the language information. Language classes can be used as a conducive place for learning and learners can learn foreign languages inductively.

Because language classes are not only learning in which the form of the game but also the activeness of learners in the classroom, usually this class is suitable for those who can adapt well. Formal classes are usually not suitable for those under the age of 7 because teaching orientation is not to play. Games are just one of activity or used as an introduction in delivering linguistic material to be more 
attractive. Those aged 7-12 years or more than 12 years can adapt better in this model of learning in the classroom because the material is taught through an exploration model. The level of teaching with class situations for children over 12 years old is high, and moderate for students aged 7-12 years but decreases to low levels for children under 7 years of age. This happens when students over the age of 7 tend to learn a foreign language or a second language with an implementation model and they know that they are learners. They have maturity that suits the class situation that requires concentration, attention, and the need to sit for a long time in class. According to Cheydleur (1932) and Thorndike (1928) as cited by Steinberg, the right age for second language learning or foreign languages is when learners can understand the reasons for learning and thinking like adults, they also have high levels of memory and motor skills. The age that fits this model is around the age of 10 years.

\section{Motivation and Attitude}

In language learning both the language as a second language or a foreign language, the learner's internal factors greatly support the success of the advocate so that the acquisition will look more natural. Both natural learning situations that are suitable for children inductively and class situations that are suitable for children over 7 years, or their psychological factors in seeing language as both a second language and a foreign language will not be separated by the presence of motivation and attitudes towards the language.

Motivation in learning and acquiring foreign languages or second languages will be seen when learners think about the importance of the language as a means of communication. Because this will not happen for children aged 0-4 / 5 who tend to acquire language unconsciously. But after the age of $4 / 5$ years children have thought about the importance of language for their social interests such as playing with friends. This is where motivation starts to play a role.

As with the classroom learning model that tends to be planned, motivation plays a very dominant role because the learner is placed in a certain situation. They are informed if they want to succeed to master the language the level of motivation must be high. Many theories state that motivation or learning goals are necessary in teaching languages other than mother tongue. The desire to be proficient and to 
integrate for the sake of intelligence is better than learning a second language or a foreign language for other purposes, for example to get a job or something. As Staib in Derakhsan (2015) which states It is common that young students learn faster and easier than adult learners in foreign language classes. Most adults are excited in learning a new language and improving language abilities, but keeping them motivated to learn throughout the course may be difficult. Adults are different from the young students in motivation in oral activities. Adult learners are not only self-motivated, but also set goals to attain them in future. Language acquisition can be another goal set by an adult person to be achieved. On the one hand, young learners are in a more beneficial position, because their parents and teachers recognize some language abilities in them or simply decide that such skills and knowledge may be important for them in future. (Ismail, 2016).

The attitude to acquire and learn a foreign language or a second language also greatly determines the level of success of mastering a second language or foreign language. Attitudes that are negative towards languages other than mother tongue can disrupt the memory process and focus on the language. So a lot of learning or the acquisition of target languages fails because the people involved in the process have lack of integrity. Many variations that influence the negative attitudes of language learners, usually associated with different cultures that affect the personality and social environment of the learner. This negative attitude is also influenced by age factors when learners begin to think about the importance of the need to learn the target language though they are in an environment that is very different from their natural situation. The critical age for knowing attitudes in language acquisition and language teaching starts from 4/5 years of age when they begin to think of the need for a second language or foreign language for their social interests, such as playing with peers despite of different cultural and linguistic backgrounds.

\section{CONCLUSION}

Learning a second or foreign language in accordance with the intended purpose or the acquisition of a second/foreign language can succeed if the people involved have the same goal, namely to communicate and integrate with the discussion of cloth other than the mother tongue. The level of natural success that tends to be 
suitable for children will also succeed when the role of parents or friends is also high. Parents not only as motivators but also as controllers of children's language acquisition (not so for adults who learn target languages). Because children tend to accept the language without filtering so it is hoped that the process of acquiring good and correct language can work well. Such conditions can also increase motivation and good language attitude so that children can also be actively involved in classroom learning models that tend to require attention and high concentration.

Likewise, on the contrary for adults, they must be able to anticipate various obstacles in the acquisition and teaching of language by thinking that even though the language is not their native language but it is a mean of communication. When they are required to go directly to the original foreign language environment, all inherent cultural attributes must be ruled out for the smooth mastery of the second/foreign language. One thing that needs to be underlined is the variety of languages is only a variety of universities of one language purpose, namely communication regardless of cultural differences, background or differences in the language itself. Age cannot be a benchmark for the success rate of mastering a second/foreign language other than mother tongue as long as the people involved have a desire to use the foreign language or the second language for the purpose of integrating and socializing. Diversity is unique but unique must not be always different.

\section{References}

Bloom, R., Mullins, J., \& Paternostro, P. (1996). Changes in Processing Adverbial Conjuncts throughout Adulthood. Applied Psycholinguistics, 17, 105-116.

Derakhsan, A., Tahery, F., \& Mirarab, N. (2015). Helping Adult and Young Learners to Communicate in Speaking Classes with Confidence. Mediterranean Journal of Social Sciences, 6(2). https://doi.org/10.5901/mjss.2015.v6n2p520

Hamrick, P., Lum, J. . A. ., \& Ullman, M. T. (2018). Child first language and adult second language are both tied to general-purpose learning systems. Proceeding of the National Academy of Science, 1487-1492. https://doi.org/https://doi.org/10.1073/pnas.1713975115 
Harley, \& Doug. (1997). Language Aptitude And Second Language Proficiency In Classroom Learners Of Different Starting Ages. Journal of Studies in Second Language Acquisition, 19, 379-400.

Hoque, M. E. (2017). An Introduction to the Second Language Acquisition. : : Publication of the Journal of EFL Education and Research (JEFLER), 1-23.

Ismail, M. (2016). Investigating The Ways Young Learners Differ From Adults In The Context Of EFL/ESL.

Krashen, S. D. (1981). Second Language. Acquisition and Second Language. Learning. Oxford: Pergamon.

Major, C. A. (2014). The Effect of Age on Second Language Acquisition in Older Adults. Provo.

Oroji, M. R., \& Ghane, A. (2014). Are Young Learner's Better Learners Of Foreign Language Learning Or Adults? Procedia - Social and Behavioral Science, 136, 84-88.

Oyama, S. (1976). A Sensitive Period for the Acquisition of a Non Native Phonological System. Journal of Psycholinguistic Research, 5(3), 261-283.

Prestonn, D. . (1989). Sociolinguistics and Second Language Acquisition. Oxford: Blackwell.

Schuman, J. H. (1978). The relationship of pidginization, creolization, and Decreolization to second language acquisition. Language Learning, 28.

Steinberg, D. (1982). Psycholinguistics: language, mind, and world. Longman.

Suryantari, H. (2018). Children and Adults in Second-Language Learning. Teaching of English Learning and Literature (TELL), 6(1). https://doi.org/DOI: 10.30651/tell.v6i1.2081 
